\title{
Synthesis, Characterization and Gas Separation Properties of Polyimides Containing Fluorene Units
}

\author{
YunHua $\mathrm{Lu}^{1,2, \mathrm{a}^{\star}}$, MingYue Fei ${ }^{1, \mathrm{~b}}$, Xin $\mathrm{Jin}^{2, \mathrm{c}}$, GuoYong Xiao ${ }^{1, \mathrm{~d}}$, ZhiZhi Hu${ }^{1, \mathrm{e}}$, \\ TongHua Wang ${ }^{2, f^{*}}$ \\ ${ }^{1}$ School of Chemical Engineering, University of Science and Technology Liaoning, Anshan, \\ Liaoning, China, \\ ${ }^{2}$ School of Chemical Engineering, Dalian University of Technology, Dalian, Liaoning, China

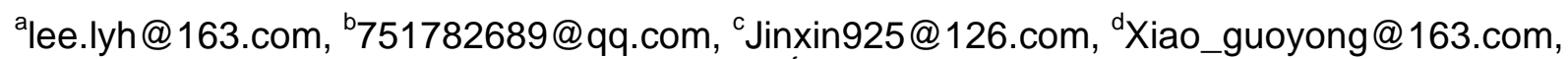 \\ ehuzhizhi@163.com, 'wangth@dlut.edu.cn
}

Keywords: Polyimide; Flourene; Gas separation properties; Solubility; Structure and properties Abstract. The six kinds of polyimides(PIs) containing fluorene units were prepared from 9,9'-bis(4-aminophenyl)fluorene(BAF) with various dianhydrides including 2,2'-bis-(3,4-dicarboxyphenyl)hexafluoropropane dianhydride(6FDA), 3,3',4,4'-biphenyltetracarboxylic dianhydride(BPDA), 4,4'-oxydiphthalic anhydride(ODPA), 3,3',4,4'-biphenyltetracarboxylic dianhydride(BTDA), pyromellitic dianhydride(PMDA) and 1,2,3,4-cyclobutanetetracarboxylic dianhydride(CBDA) via chemical imidization. Wide-angle X-ray diffractograms revealed that the polymers were amorphous. Most of the polyimides exhibited good solubility and could be readily dissolved in various solvents such as $N$-Methyl-2-pyrrolidone(NMP), $N, N$-dimethylacetamide(DMAc), $N, N$-dimethylformamide(DMF), and so on. The polyimide was thermally treated at $300^{\circ} \mathrm{C}, 420^{\circ} \mathrm{C}$ and $550^{\circ} \mathrm{C}$ for further carbonization. Gas permeation properties for $\mathrm{O}_{2}$ and $\mathrm{N}_{2}$ of the PI-BPDA and PI-CBDA membranes were investigated. The permeability coefficients and selectivity for $\mathrm{O}_{2}$ and $\mathrm{N}_{2}$ of polyimide were obtained. With the increase of thermal treatment temperature, the permeability for $\mathrm{O}_{2}$ and $\mathrm{N}_{2}$ of polyimides increased, but the selectivity decreased. The gas separation mechanism for $\mathrm{O}_{2}$ and $\mathrm{N}_{2}$ was mainly molecular sieving.

\section{Introduction}

Polyimide membranes have emerged as an effective technology for certain gas separations including $\mathrm{CO}_{2}, \mathrm{~N}_{2}, \mathrm{CH}_{4}, \mathrm{O}_{2}, \mathrm{H}_{2}$ and so on. So more and more specialists have interested in this class of polymers and it has been growing steadily. Since the first report of the membrane-based separation concept by Graham in $1866^{[1]}$, membranes have been developed and utilized on an industrial scale for air separation, hydrogen recovery, and hydrocarbon/light gas separation. An advantage of polymeric composite membranes is that their gas permeability and selectivity can be controlled by the combination of various polymer components ${ }^{[2,3]}$. Among the various membrane materials used for gas separation application, aromatic polyimides are a class of high-performance materials.

Aromatic polyimides are an important class of high performance polymers, wholly aromatic polyimides show excellent characteristic, such as very high thermal stability, perfect mechanical, wonderful electrical behavior, low flammability, superior chemical resistanceand so on ${ }^{[4,5]}$. It is well-known that these polymers have been found wide uses in many industrial fields such as microelectronic applications, electrical materials, adhesives, composites, space industry and separation membranes. But at the same time, aromatic polyimides are generally difficult to process due to their poor solubility in organic solvents. What's more the highly regular and rigid polymer backbones and the formation of inter molecular hydrogen bonding of these polyimides are generally responsible for the difficulty of processing. Extremely high glass transition or melting temperatures due to their rigid backbones which limited their applications.

To overcome such difficulties, polymer's structure modification becomes necessary. Much efforts have been directed toward to modify their chemical structures to change their properties regard to a specific application or to a particular property without sacrificing their excellent properties via 
structure modification. The successful approaches employed for those purposes include: introduction of flexible bonds ${ }^{[6]}$, flourene groups ${ }^{[7]}$, unsymmetrical ${ }^{[8]}$ and alicyclic units ${ }^{[9]}$ into the macromolecular backbone. These structural modifications could disturb regularity of chain packing, thus provide better solubility. Introducing aromatic structures and thermally stable flourene units into the polymer backbone is a promising method of modifying the properties of the polyimide. The introduction of certain functional groups into the polyimides, which include both amine and anhydride components, can generate polyimides with special properties.

In this study, the synthesis of six kinds of poly(amic acid)s derived from 9,9'-bis(4-aminophenyl)fluorene (BAF) with various dianhydrides were described. Fluorene group was introduced into polyimide backbone. Here, the polyimide membrane was thermally treated at $300^{\circ} \mathrm{C}$, $420^{\circ} \mathrm{C}$ and $550^{\circ} \mathrm{C}$, and the corresponding gas separation properties were measured. The solubility, morphology, and thermal properties of the obtained polymers were also investigated.

\section{Experimental}

Materials. Chemicals of high purity were obtained from Shanghai Research Institute of Synthetic Resins which include 2,2'-bis-(3,4-dicarboxyphenyl) hexafluoropropane dianhydride (6FDA), 3,3',4,4'-biphenyltetracarboxylic dianhydride (BPDA), 4,4'-oxydiphthalic anhydride (ODPA), 3,3',4,4'-biphenyltetracarboxylic dianhydride (BTDA) and pyromellitic dianhydride (PMDA). The five monomers were dried at $200^{\circ} \mathrm{C}$ in a vacuum oven for four hours before use. The 9,9'-bis(4-aminophenyl)fluorene (BAF) and 1,2,3,4-cyclobutanetetracarboxylic dianhydride (CBDA) were synthesized in our laboratory. The reagents $N$-methyl-2-pyrrolidinone (NMP), acetic anhydride and pyridine were obtained from Sinopharm Chemical Reagent Co., Ltd..

Synthesis of Polyimide. Chemical imidization is a common method to convert poly (amic acid)(PAA) to polyimide. In scheme 1, six kinds of PAAs were synthesized to prepare polyimides via chemical imidization. For a typical synthesis procedure, a flask was charged with 5 mmol of BAF and $22.46 \mathrm{~g}$ of distilled NMP. The mixture was stirred with a mechanical stirrer at room temperature until the diamine dissolved completely (approximately half an hour). Then, $5 \mathrm{mmol}$ of 6FDA was then added and the resulting mixture was stirred for roughly $12 \mathrm{~h}$ to form the poly (amic acid) solution. Dense membrane was prepared by casting $15 \mathrm{wt} \%$ PAA in NMP onto a glass plate. Then gently spread it into a film with a glass rod and the PAA film was heated under vacuum at $40^{\circ} \mathrm{C}$ for 24 hours.

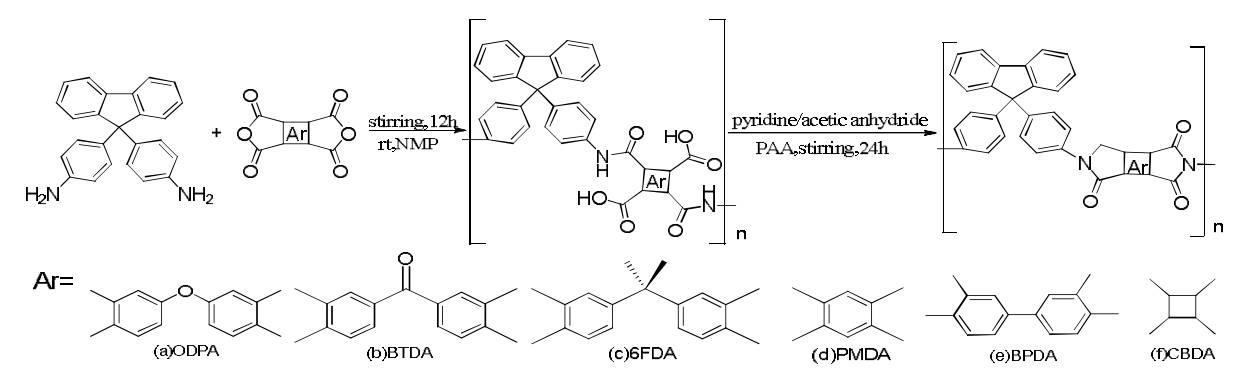

Fig. 1. Preparation of polyimides by chemical imidization

Then $25 \mathrm{mmol}$ pyridine and $25 \mathrm{mmol}$ acetic anhydride were added dropwise into the rest of the PAA solution. The solution was stirred with a mechanical stirrer for another $24 \mathrm{~h}$. Then the solution was poured into a large amount of water under constant stirring and collected on a filter. It was named as PI-6FDA. Finally, polyimide was heated at $80^{\circ} \mathrm{C}$ for one hour, $100^{\circ} \mathrm{C}$ for $1 \mathrm{~h}, 150^{\circ} \mathrm{C}$ for $1 \mathrm{~h}, 200^{\circ} \mathrm{C}$ for $1 \mathrm{~h}, 250^{\circ} \mathrm{C}$ for $1 \mathrm{~h}$ and $300^{\circ} \mathrm{C}$ for $0.5 \mathrm{~h}$ to further dry it. All other polyimides were prepared using the same procedure.

Measurement. Solubility was determined qualitatively by placing $10 \mathrm{mg}$ of polymer into one $\mathrm{mL}$ of solvent. After ultrasound for $10 \mathrm{~min}$, the solubility of the polyimide was observed. Fourier transform infrared spectra (FT-IR) was recorded in the range of $4000-500 \mathrm{~cm}^{-1}$ by Fourier Transform Infrared WQF-200 spectrometer. The average scanning frequency of the instrument were 16 times and the resolution of $4 \mathrm{~cm}^{-1}$. The mix gas permeability coefficients and selectivity for $\mathrm{O}_{2}$ and $\mathrm{N}_{2}$ were measured 
using a constant volume variable pressure method at $30^{\circ} \mathrm{C}^{[10]}$. The pressure was regulated at $0.1 \mathrm{MPa}$ by a pressure regulator. To ensure a good reproducibility of polyimide membranes, the replicative experiments were performed three times. The gas permeation data presented in the article are referred to the average values. X-ray diffraction (XRD) pattern was recorded in the reflection mode at room temperature using a diffractometer created by PANalytical B.V. which uses $\mathrm{Ni}$ filtered $\mathrm{Cu}-\mathrm{K} \alpha$ (wavelength $\lambda=1.541 \AA$ ) radiation. The scanning rate was $0.5^{\circ}(2 \theta) \cdot \mathrm{min}^{-1}$ in a $2 \theta$ range of $5-40^{\circ}$. The average $d$-spacing was determined based on the Bragg's law:

$$
2 d \sin \theta=\mathrm{n} \lambda
$$

where $d$ is the $d$-spacing, $\theta$ the scattering angle and $\mathrm{n}$ is an integer number $(1,2,3, \ldots)$ related to the Bragg order.

\section{Results and discussion}

Structure of polyimides. The structures of these polyimides were confirmed by FT-IR spectroscopy. Thus, FT-IR spectra showed characteristic absorption bands of polyimides (Fig.1). The six samples had the similar peaks. The deformation vibration band of N-H of the amino was at $720 \mathrm{~cm}^{-1}$. In addition, the $\mathrm{N}-\mathrm{H}$ of the amino also had deformation vibration band near $1500 \mathrm{~cm}^{-1}$. There was also a strong and broad absorption band between $3000 \mathrm{~cm}^{-1}$ and $3250 \mathrm{~cm}^{-1}$. It was the stretching vibration band of $\mathrm{N}-\mathrm{H}$ of the amino. The stretching vibration of $\mathrm{C}-\mathrm{N}$ and $\mathrm{C}=\mathrm{O}$ were respectively around 1100 $\sim 1375 \mathrm{~cm}^{-1}$ and $1720 \mathrm{~cm}^{-1}$ in the group of $-\mathrm{CONH}$. According to the literature on the infrared spectrum analysis of the polyimide, the asymmetry and symmetry stretching vibration absorption bands of the $\mathrm{C}=\mathrm{O}$ were detected around $1780 \mathrm{~cm}^{-1}, 1720 \mathrm{~cm}^{-1}$ and $727 \mathrm{~cm}^{-1}$. And the stretching vibration of the C-N occurred at around $1374 \mathrm{~cm}^{-1}$. The presence of aromatic imide group was confirmed.

XRD was used to determine $d$-spacing values for polyimide and to determine if any regions of crystallinity existed. The $d$-spacing values were calculated according to the well-known Eq.(1). In Fig.3, the diffraction peak position changed with various components of polyimides, resulting in the $d$-spacing data changing. As shown in Fig. 3, the broad and amorphous halos observed in all samples confirmed that the polymers were completely amorphous. The excellent arrangement resulted from the completely rigid main chain structure of polyimides.

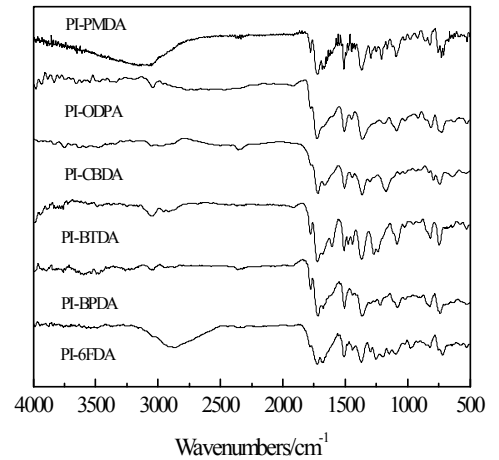

Fig.2 FT-IR spectra of the six polyimides

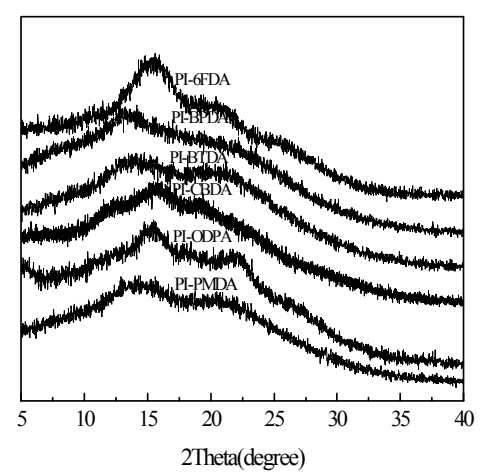

Fig.3 XRD curves of the six polyimides

Solubility. The solubility behavior of polyimides depended on their chain packing density and intermolecular interactions. The BAF diamine with flourene units had the structure of rigid coplanar and bulky side group, so the rigidity of the polyimide backbone was strong. With the introduction of the bulky side chain, the solubility of the polyimides obtained a significant improvement. The solubility of the polyimides in several organic solvents was summarized in Table 1. 
Table 1 Solubility of polyimides

\begin{tabular}{ccccccc}
\hline solvents & PI-ODPA & PI-BTDA & PI-6FDA & PI-PMDA & PI-BPDA & PI-CBDA \\
\hline DMF & ++ & ++ & ++ & ++ & ++ & ++ \\
DMAc & ++ & ++ & ++ & ++ & ++ & ++ \\
DMSO & ++ & + & ++ & ++ & - & ++ \\
NMP & ++ & ++ & ++ & ++ & ++ & ++ \\
THF & ++ & ++ & ++ & ++ & + & + \\
acetone & - & - & ++ & - & - & ++ \\
ethyl acetate & - & - & + & - & - & + \\
acetonitrile & - & - & - & - & - & - \\
\hline
\end{tabular}

++: soluble; +: partially soluble; -: insoluble

The solubility of polyimides was tested quantitatively in various solvents. As you can see from Table 1, the polyimides derived from six kinds of dianhydrides showed good solubility. Most of the polyimides were soluble in the test solvents including strong aprotic polar solvents DMF, DMAc, DMSO, NMP, and THF. They were insoluble in organic solvents such as acetone, ethyl acetate and acetonitrile. Especially, PI-6FDA and PI-CBDA exhibited best solubility, which could also dissolve in acetone, THF and ethyl acetate. The reason for it is that CBDA with non-planar structure increase the distance between the polyimide molecules to make the solvent to permeate. The good solubility of PI-6FDA derived from BAF might be due to the presence of bulky fluorene and $-\mathrm{CF}_{3}$ groups in the diamine moiety, which further increase the disorder in the chains and hinder dense chain stacking, thereby reducing the interchain interactions and so enhancing solubility.

Gas separation properties. The mix gases permeability for $\mathrm{O}_{2}$ and $\mathrm{N}_{2}$ was measured at $30^{\circ} \mathrm{C}$, and their selectivity was calculated. Table 2 presented mix gases permeability coefficients and the selectivity of PI-CBDA and PI-BPDA. The polyimide was heated at $300^{\circ} \mathrm{C}$ for one hour and then $420^{\circ} \mathrm{C}$ for $30 \mathrm{~min}$ for preoxidation. At last, the sample was further carbonized at $550^{\circ} \mathrm{C}$ for $30 \mathrm{~min}$. For PI-BPDA, the permeability for $\mathrm{O}_{2}$ and $\mathrm{N}_{2}$ were respectively $1.0280 \mathrm{GPU}$ and $1.7868 \mathrm{GPU}$ at $300^{\circ} \mathrm{C}$. And the selectivity was 1.1851 . After the thermal treatment at $420^{\circ} \mathrm{C}$, the permeability for $\mathrm{O}_{2}$ and $\mathrm{N}_{2}$ were up to 2.6875 GPU and 2.7116 GPU. At the same time, the selectivity decreased to 0.8930 . After the carbonization at $550^{\circ} \mathrm{C}$, all gas permeability data increased, but the selectivity decreased. The permeability for $\mathrm{O}_{2}$ was $4.2941 \mathrm{GPU}$ and for $\mathrm{N}_{2}$ was 3.6235 GPU. Meanwhile the selectivity coefficient was 0.5753 . It can be seen that the mix gas permeability of PI-BPDA increased with the thermally treated temperature increasing, but the selectivity for $\mathrm{O}_{2}$ and $\mathrm{N}_{2}$ decreased. For another PI sample, the data showed a similar trend. As you can see from Table 2, the permeability for $\mathrm{O}_{2}$ and $\mathrm{N}_{2}$ were $0.4010 \mathrm{GPU}$ and $0.2418 \mathrm{GPU}$, and the selectivity was 1.6584 at $300^{\circ} \mathrm{C}$. And at $420^{\circ} \mathrm{C}$, they were $0.6455 \mathrm{GPU}$ and $0.4822 \mathrm{GPU}$, and the selectivity was 1.3074 . Then after thermal treatment at $500^{\circ} \mathrm{C}$, the permeability for $\mathrm{O}_{2}$ was $0.6714 \mathrm{GPU}$ and for $\mathrm{N}_{2}$ was 0.5989 GPU. The selectivity for $\mathrm{O}_{2}$ and $\mathrm{N}_{2}$ were 1.0585 at $550^{\circ} \mathrm{C}$. Because of the high temperature treatment, some region of the polyimide backbone was pyrolyzed to produce some small molecule to make some channel. Therefore, with the increase of temperature, the permeability of PI sample was improved, but the selectivity decreased. Compared with PI-BPDA, PI-CBDA exhibited lower gas permeability because the thermal stability of PI-CBDA was poorer than that of PI-BPDA, where some polyimide structure was collapsed. The kinetic diameter of $\mathrm{O}_{2}$ was $0.346 \mathrm{~nm}$, and $\mathrm{N}_{2}$ was $0.364 \mathrm{~nm}$. The permeability coefficient of $\mathrm{O}_{2}$ was bigger than that of $\mathrm{N}_{2}$, which indicated that the gas separation mechanism for $\mathrm{O}_{2}$ and $\mathrm{N}_{2}$ was mainly molecular sieving. 
Table 2 Gas permeability and selectivity of polyimides measured at $0.1 \mathrm{MPa}$ and $30^{\circ} \mathrm{C}$

\begin{tabular}{llllc}
\hline \multirow{2}{*}{ Samples } & \multirow{2}{*}{$\mathrm{T} /{ }^{\circ} \mathrm{C}$} & \multicolumn{2}{c}{ Permeability $\left(\mathrm{GPU}^{\mathrm{a}}\right)$} & Selectivity \\
\cline { 3 - 5 } & & $\mathrm{O}_{2}$ & $\mathrm{~N}_{2}$ & $\mathrm{O}_{2} / \mathrm{N}_{2}$ \\
\hline PI-BPDA & 300 & 1.7868 & 1.0280 & 1.1851 \\
PI-BPDA & 420 & 2.7116 & 2.6875 & 0.8930 \\
PI-BPDA & 550 & 4.2941 & 3.6235 & 0.5753 \\
PI-CBDA & 300 & 0.4010 & 0.2418 & 1.6584 \\
PI-CBDA & 420 & 0.6455 & 0.4822 & 1.3074 \\
PI-CBDA & 550 & 0.6714 & 0.5989 & 1.0585 \\
\hline
\end{tabular}

${ }^{\mathrm{a}} \mathrm{GPU:}$ The unit of permeability coefficients; $1 \mathrm{GPU}=10^{-10} \mathrm{~m}^{3} \cdot \mathrm{m}^{-2} \cdot \mathrm{s}^{-1} \cdot \mathrm{Pa}^{-1}$

\section{Conclusions}

The BAF diamine and six kinds of anhydrides were used to synthesize the polyimides through the classical two-step method. FT-IR, XRD, solubility and gas permeability of membrane were carried out to characterize the structure and properties of polyimide containing fluorine units. Wide-angle X-ray diffractograms (XRD) revealed that the polymers were amorphous. Most of the polymers exhibited good solubility and could be readily dissolved in various solvents such DMF, DMAc, NMP, and so on. Gas permeation properties for $\mathrm{O}_{2}$ and $\mathrm{N}_{2}$ of the polyimide membranes PI-BPDA and PI-CBDA at different thermally treated temperature were investigated. With the increase of thermal treatment temperature, the permeability for $\mathrm{O}_{2}$ and $\mathrm{N}_{2}$ of polyimides containing fluorene units increased, but the selectivity decreased. The gas separation mechanism for $\mathrm{O}_{2}$ and $\mathrm{N}_{2}$ was mainly molecular sieving.

Acknowledgement. This work was financially supported by the National Natural Science Foundation of China (Grant No. 21406102, 21176036, 21376037, 21436009) and China Postdoctoral Science Foundation (Grant No. 2014M560212).

\section{References}

[1] T. Graham, On the absorption and dialytic separation of gases by colloid septa, Philosophical Transactions of the Royal Society of London, J. Chem. Soc. 20(1867)235-288.

[2] S.H. Park, K.J. Kim, W.W. So, S.J. Moon, S.B. Lee, Gas separation properties of 6FDA-based polyimide membranes with a polar group, Macromol. Reson. 11(2003)157-162.

[3] Y. Tsuda, M. Kojima, T. Matsuda and J. M. Oh, Soluble polyimides based on long-chain alkyl groups via amide linkages, J. Polym. 40(2008) 354-366.

[4] Z. Rafiee, S. Khalili, Synthesis and characterization of highly soluble and thermally stable new polyimides based on 3,5-diamino benzoyl amino phenyl-14H-dibenzo[a,j]xanthene, Polym. Bull. 70(2013)2423-2435.

[5] D Wilson, H.D. Stenzenberger, and P.M. Hergenrother, Polyimides, Blackie, London, 1990, pp. 58.

[6] H.S. Lee, S.Y. Kim, Synthesis of poly(arylene ether amide)s containing $\mathrm{CF}_{3}$ groups by nitro displacement reaction of AB-type monomers, Macromol. Rapid Commun. 23(2002)666-671.

[7] S.H. Hsiao, C.P. Yang, M.H. Chuang, S.J. Lin, Synthesis and characterization of novel aromatic polyamides with polyalicyclic cardo groups, J. Polym. Sci. Part A: Polym. Chem. 37(1999) 4510-4521. 
[8] R.R. Pal, P.S. Patil, M.M. Salunkhe, N.N. Maldar, P.P. Wadgaonkar, Synthesis, characterization and constitutional isomerism study of new aromatic polyamides containing pendant groups based on asymmetrically substituted meta-phenylene diamines, Eur. Polym. J. 45(2009) 953-959.

[9] C.P. Yang, Y.Y. Su, F.Z. Hsiao, Synthesis and properties of organosoluble polyimides based on 1,1'-bis[4-(4-amino-2-trifluoromethylphenoxy)phenyl]cyclohexane, Polymer, 45(2004) 7529-7538.

[10] C.W. Song, T.H. Wang, X.Y. Wang, J.S. Qiu and Y.M. Cao, Preparation and gas separation properties of poly(furfuryl alcohol)-based C/CMS composite membranes, Sep. Purif. Technol. 58(2008) 412-418. 